\title{
Towards a better understanding of landscape patterns and ecosystem processes of the Mongolian Plateau
}

\author{
Jingyun Fang $\cdot$ Yongfei Bai $\cdot$ Jianguo Wu
}

Received: 5 September 2015/Accepted: 6 September 2015/Published online: 23 September 2015

(C) Springer Science+Business Media Dordrecht 2015

\section{The changing landscapes of the Mongolian Plateau}

The Mongolian Plateau has been well known to the world as the cradle of the Mongolian nomadic civilization. The plateau is located in the hinterland of temperate Asia, consisting primarily of two entities: the Inner Mongolia Autonomous Region of China (Inner Mongolia hereafter) and the entire territory of Mongolia (formerly the Republic of Mongolian). The Mongolian Plateau has a total area of 2.75 million $\mathrm{km}^{2}$ $\left(1.18 \mathrm{~km}^{2}\right.$ for Inner Mongolia and 1.57 million $\mathrm{km}^{2}$ for Mongolia) and a population of about 28 million (25

\section{J. Fang · Y. Bai}

State Key Laboratory of Vegetation and Environmental Change, Institute of Botany, Chinese Academy of Sciences, Beijing 100093, China

J. Fang $(\bowtie)$

Department of Ecology, College of Environmental Sciences, and Key Laboratory of Earth Surface Processes of the Ministry of Education, Peking University, Beijing 100871, China

e-mail: jyfang@urban.pku.edu.cn

J. Wu

School of Life Sciences and School of Sustainability, Arizona State University, Tempe, AZ 85287, USA

J. Wu

Center for Human-Environment System Sustainability, State Key Laboratory of Earth Surface Processes and Resource Ecology, Beijing Normal University, Beijing 100875, China million for Inner Mongolia and 3 million for Mongolia in 2015). It has a hyper-continental climate, with most rainfall concentrated in summer and a long and cold winter. In the past millions of years, the plateau has changed from an ancient ocean to a forested region and then to a dryland region (Wu et al. 2015b). The plateau's vegetation now is dominated by steppes and deserts which account for 44 and $34 \%$ of the total land area, respectively, and also includes forests (14\%), cropland (5\%), and alpine vegetation (3\%) (Fig. 1; Zhao et al. 2014). The plateau is also dotted with numerous lakes, which have been disappearing or shrinking in size rapidly during the past three decades (Tao et al. 2015).

Once ruled by the Great Mongol Empire founded by Genghis Khan, whose army and herds roamed across the Eurasian grassland region and beyond during the thirteenth century, the Mongolian Plateau has experienced increasingly rapid landscape transformations since the late Qing Dynasty due to both human and natural factors (Wu et al. 2015b). The most dramatic landscape and ecological changes occurred during the past several decades. In the past 30 years, human activities have become more intensive and extensive, with increasing human population (especially in Inner Mongolia), livestock overgrazing, coal and mineral mining, and rapid urbanization (Tao et al. 2015; Wu et al. 2015a, b). Meanwhile, the climate has become warmer and drier, with annual mean temperature increasing by $1.2^{\circ} \mathrm{C}$ and annual precipitation generally decreasing since the mid-1990s Zhao et al. 

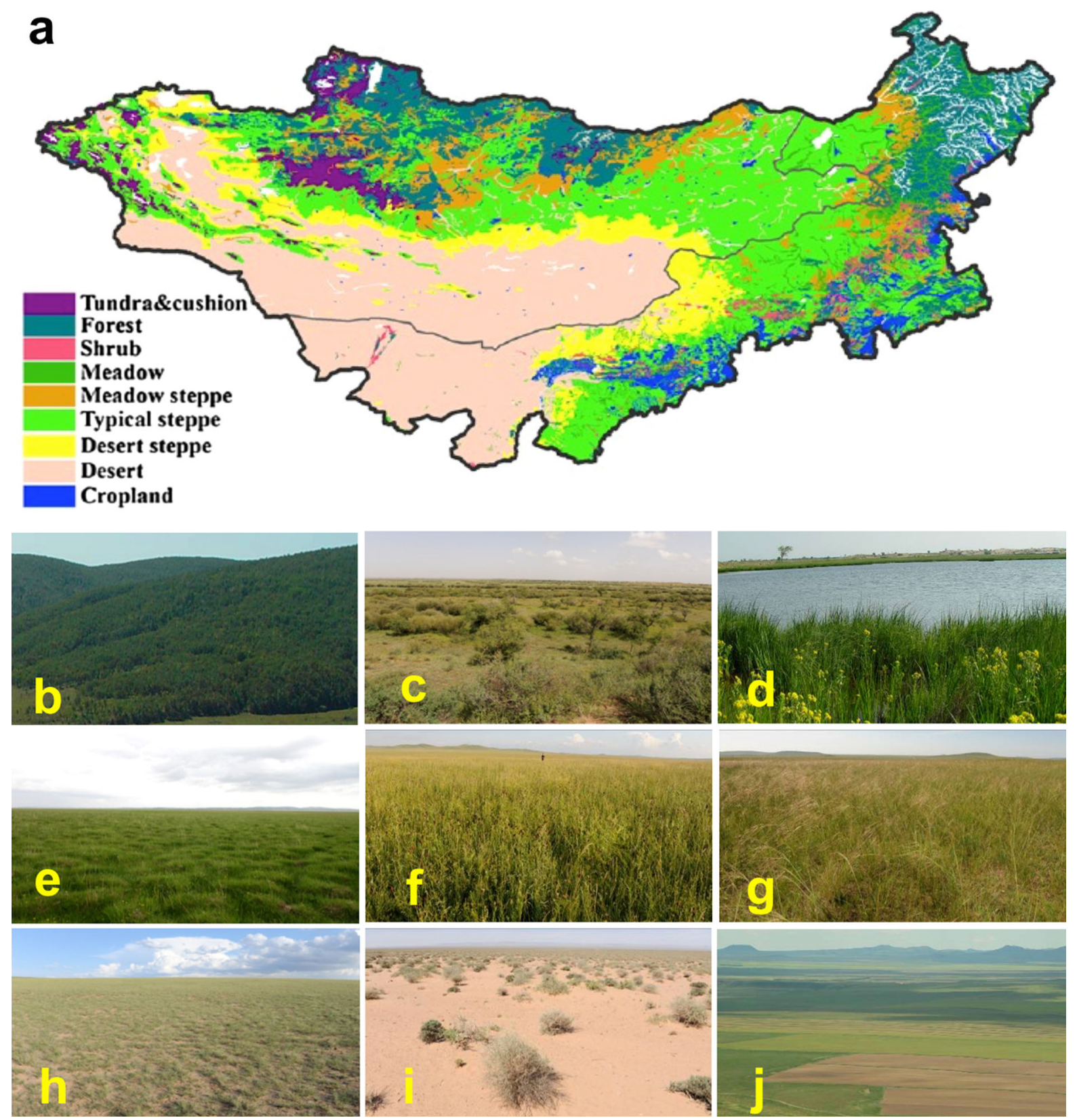

Fig. 1 Vegetation of the Mongolian Plateau. a Vegetation map, b Forest, c Shrub, d Lake, e Meadow, f Meadow steppe, g Typical steppe, $\mathbf{h}$ Desert steppe, $\mathbf{i}$ Desert, and $\mathbf{j}$ Cropland

(2014). The human activities have strongly altered landscapes and ecosystems across the plateau, and the environmental sustainability of this region is facing great challenges.

The main goal of this special issue was, therefore, to promote a better understanding of the ecology and sustainability of the Mongolian Plateau. The landscape transformations and ecosystem changes of the
Mongolian Plateau are not unique, as most of the world's drylands, together accounting for more than $40 \%$ of the global land surface area, have all changed profoundly and become increasingly unsustainable during the past few centuries (Reynolds and Smith 2002; MEA 2005). Thus, these studies from the plateau also have relevant implications for arid and semiarid landscapes around the world. 


\section{About this special issue}

This special issue consists of 16 papers which discussed a range of landscape and ecosystem issues, with a focus on the steppes of the Mongolian Plateau. We categorized them into three topics: (1) land use change and vegetation dynamics, (2) biodiversity and community structures along environmental gradients, and (3) human impacts on ecosystem processes. The three topics are interrelated as landscape patterns affect the spatiotemporal dynamics of biological communities and ecosystem processes, and both natural and human factors simultaneously influence biodiversity, ecological processes, and landscape heterogeneity across the Mongolian Plateau (Fig. 2).

Land use change and vegetation dynamics

The unique landscape of the Mongolian Plateau cultivated the time-honored nomadic culture, with an evolving land-use history shaped by changing humanenvironment interactions. Wu et al. (2015b) review the evolution of the landscapes of Inner Mongolia from antiquity to the present. Landscape changes have been much greater in both scope and intensity in Inner Mongolia than in the outer Mongolia, particularly during the past several decades. Inner Mongolia has experienced a series of profound land transitions from localized primitive agriculture that occurred in prehistoric times to broad-scale nomadic pastoralism that lasted for a few thousand years, and to sedentary pastoralism with increasing agriculture and urbanization since the 1960s.

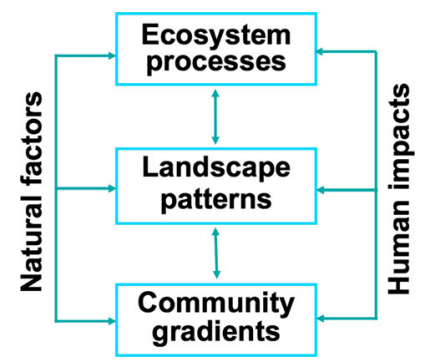

Fig. 2 A conceptual diagram adopted in this special issue, showing the relationship among the three topics: land use change and vegetation dynamics, biodiversity and biological communities along environmental gradients, and human impacts on ecosystem processes in the Mongolian Plateau
These land use patterns have long been shaped by the interactions between nomadic pastoralism and agrarian culture. These land use changes have resulted in extensive changes in vegetation across the Mongolian Plateau. Zhao et al. (2014) quantified the changes in the spatial pattern of vegetation in the Mongolian Plateau from 1982 to 2011, based on NDVI derived from remote sensing imagery. For the entire plateau, a significantly positive trend in the growing season NDVI was observed during 1982-1998, but since then the NDVI has not shown a consistent increase. Although vegetation in the outer Mongolia is often considered to be in better conditions than that in Inner Mongolia, the satellite-based study indicated that the average growing season NDVI, reflecting vegetation coverage and biomass production, was $22.2 \%$ higher in Inner Mongolia than in the outer Mongolia. Both climatic conditions and human activities have affected the vegetation changes across the plateau.

In a related study, Zhou et al. (2015) provided more details of vegetation changes in four mega-sandy lands in Inner Mongolia. Consistent with Zhao et al. (2014), they also found that precipitation was a major determinant for the spatial patterns and inter-annual variations of NDVI at the regional scale, whereas human activities played a more important role on the local scale. Chen et al. (2014a) investigated the shrub encroachment which occurred widely in Inner Mongolia, and indicated that precipitation was the major controller for shrub cover and patch size, while temperature was the primary factor influencing shrub height and patch density. Thus, shrub cover and patch size were greater in dry and warm areas than moist and cool sites. Woody encroachment in grasslands has been reported worldwide, and is often driven by a suite of interacting factors, including climate, grazing, and land management practices (Matson and Bart 2013). As in other arid regions around the world, shrub encroachment in the Mongolian Plateau can potentially change landscape patterns and ecosystem processes profoundly and permanently.

Biodiversity and community structures along environmental gradients

The Mongolian Plateau is spatially extensive, with pronounced environmental gradients driven primarily by precipitation and temperature on broad scales. Thus, it is an ideal region to examine the landscape 
patterns of structures and dynamics of different biological communities. Jiang et al. (2014) investigated the effects of taxonomic relation, density dependency, species interaction and climate variation on spatial-temporal species assemblages of rodent communities across grasslands in Inner Mongolia. They found that rodent species assemblages are well explained by environmental variables, suggesting that resource partitioning through competition and environmental filtering by climate and vegetation are important forces shaping the community structure and dynamics of small mammals. Grasshoppers are important herbivores in grasslands throughout the world. Hao et al. (2015) studied the landscape level patterns of grasshopper communities in Inner Mongolia. They found that grasshopper abundance tended to be lowest and species diversity highest in plant communities with intermediate levels of biomass and plant species richness. These results suggest that locust outbreaks in Inner Mongolia can be reduced via appropriate land use management measures.

Understanding patterns and drivers of soil microbial communities on landscape and regional scales is an important but inadequately-studied topic. Chen et al. (2014a) examined these patterns and drivers using data from 24 arid and semiarid sites, covering a broad range of community types, soils, and climatic conditions on the Mongolia plateau. They demonstrated that the total soil microbial biomass, as well as fungal, bacterial, and actinomycete biomass, increased with mean annual precipitation, soil organic carbon, total soil nitrogen, and belowground biomass, but decreased with increasing soil $\mathrm{pH}$ and mean annual temperature. Mi et al. (2014) investigated the effects of multiple abiotic and biotic factors on soil organic carbon mineralization across 12 widespread arid and semiarid ecosystems. They showed that soil moisture had a predominant control on SOC mineralization, and that mineralization potential of SOC is directly regulated by microbe activity and substrate availability.

How do the species composition and biodiversity change in the plateau at long-term scale? In order to answer this question, Li et al. (2014a, b) investigated the dynamics of community composition and species richness in a temperate grassland in Inner Mongolia between 1981-2011, after the exclusion of livestock grazing. They found that species richness and relative abundance increased between 1981 and
1991, and then declined from 1992 to 2011 mainly because of decreasing rainfall and increasing temperature. In addition, Wang et al. (2013) showed that plant species richness is highly associated with soil heterogeneity (including the magnitude and patch structure) in the Kerqin grassland, located in northeastern China.

\section{Human impacts on ecosystem processes}

Over the past several decades, both natural factors and human activities have had profound influences on the ecosystem processes in the Mongolian Plateau. Grazing and mowing are two common and strong anthropogenic driving forces. Wu et al. (2015b) performed a large-scale field manipulation experiment, the Inner Mongolian Grassland Removal Experiment (IMGRE), in a temperate steppe, Inner Mongolia to investigate how the lost of plant diversity would affect ecosystem processes. IMGRE used two plant removal protocols (complete and partial removal) and explicitly considered multiple trophic levels and grazing by grasshoppers and sheep. These authors found that the responses of ecosystem processes depended on plant functional richness and identity, as well as disturbance characteristics. In a related paper, Yuan et al. (2015) examined the effects of spatial heterogeneity on the biodiversity-ecosystem function (BEF) relationship before and after the biodiversity removal. They found that most of the variables of biodiversity and ecosystem functioning were spatially correlated to each other, and that removal treatments had significant effects on these spatial patterns.

Grazing by herbivores is an important part of the study of BEF relationships. Li et al. (2014a, b) investigated the scale dependence of grazing effects on plant diversity, based on a grazing manipulation experiment in a typical steppe of Inner Mongolia. Their study showed that the negative effect of grazing on overall species richness was attributable mainly to the loss of grazing-sensitive rare species, and that this negative effect increased with spatial scale. From the same grazing experiment, Wan et al. (2015) showed that, at intermediate levels of grazing intensity, palatable species (mainly forbs) were most severely damaged, whereas spatial heterogeneity of biomass and species composition peaked. This resulted in a U-shaped diversity-grazing intensity curve because palatable species are major contributors to plant 
diversity. These findings are at odds with the existing disturbance-diversity models and call for attention to diet selection of grazing animals in the study of diversity-grazing relationship.

Grazing is a disturbance that often leads to spatial heterogeneity of species composition, vegetation cover, and soil properties. Peng et al. (2015) investigated whether grazing would also affect plant genetic diversity in a natural grassland in Inner Mongolia, a question related to landscape genetics. They found that the genetic diversity of two dominant species (Stipa grandis and S. krylovii) varied under different grazing intensities: the highest genetic diversity was found under moderate grazing, whereas the lowest genetic diversity was associated with heavy grazing. Mowing and grazing are related but distinct ecological disturbances or land use practices. Based on monitoring data from a typical steppe over 30 years, Baoyin et al. (2015) found that the species composition of mowed grasslands was determined primarily by plant growth form (e.g., annuals, perennial bunchgrasses, perennial rhizome grasses, forbs, and shrubs and semi-shrubs). This result differs from the previous finding that plant community composition in mowed grasslands was influenced mainly by plant height and photosynthetic pathways, suggesting the importance of considering plant functional diversity in grassland management.

Acknowledgments We thank Y. Shi for his assistance in organizing this special issue. This study was partly supported by the Strategic Priority Research Program of the Chinese Academy of Sciences (\#XDA05050000) and the National Natural Science Foundation of China (\#31330012). JW's research on the Inner Mongolia grassland was supported in part by US National Science Foundation (DEB-0618193) and the Chinese Ministry of Science and Technology through the National Basic Research Program of China (2014CB954303, 2014CB954300).

\section{References}

Baoyin T, Li FY, Minggagud H, Bao Q, Zhong Y (2015) Mowing succession of species composition is determined by plant growth forms, not photosynthetic pathways in Leymus chinensis grassland of Inner Mongolia. Landscape Ecol. doi:10.1007/s10980-015-0249-6

Chen D, Mi J, Chu P, Cheng J, Zhang L, Pan Q, Xie Y, Bai Y (2014a) Patterns and drivers of soil microbial communities along a regional precipitation gradient on the Mongolia plateau. Landscape Ecol. doi:10.1007/s10980-014-9996-Z

Chen L, Li H, Zhang P, Zhao X, Zhou L, Liu T, Hu H, Bai Y, Shen H, Fang J (2014b) Climate and native grassland vegetation as drivers of the community structures of shrubencroached grasslands in Inner Mongolia. Landscape Ecol, China. doi:10.1007/s10980-014-0044-9

Hao S, Wang S, Cease A, Kang L (2015) Landscape level patterns of grasshopper communities in Inner Mongolia: interactive effects of livestock grazing and precipitation gradient. Landscape Ecol. doi:10.1007/s10980-0150247-8

Jiang G, Liu J, Xu L, Yan C, He H, Zhang Z (2014) Multiple factors determine spatial-temporal species assemblages of rodents in arid grasslands. Landscape Ecol. doi:10.1007/ s10980-014-0039-6

Li W, Zhan S, Lan Z, Wu XB, Bai Y (2014a) Scale-dependent patterns and mechanisms of grazing-induced biodiversity loss: evidence from a field manipulation experiment in semiarid steppe. Landscape Ecol. doi:10.1007/s10980014-0146-4

Li Z, Ma W, Liang C, Liu Z, Wang W, Wang L (2014b) Longterm vegetation dynamics driven by climatic variations in the Inner Mongolia grassland: findings from 30-year monitoring. Landscape Ecol. doi:10.1007/s10980-0140068-1

Matson E, Bart D (2013) Interactions among fire legacies, grazing and topography predict shrub encroachment in post-agricultural páramo. Landscape Ecol 28:1829-1840

MEA (2005) Ecosystems and human well-being: current state and trends. Island Press, Washington DC

Mi J, Li J, Chen D, Xie Y, Bai Y (2014) Predominant control of moisture on soil organic carbon mineralization across a broad range of arid and semiarid ecosystems on the Mongolia plateau. Landscape Ecol. doi:10.1007/s10980-0140040-0

Peng J, Liang C, Niu Y, Jiang W, Wang W, Wang L (2015) Moderate grazing promotes genetic diversity of Stipa species in the Inner Mongolian steppe. Landscape Ecol. doi: 10.1007/s10980-015-0227-z

Reynolds JF, Smith DMS (eds) (2002) Global desertification: do humans cause deserts?. Dahlem University Press, Berlin

Tao S, Fang J, Zhao X, Zhao S, Shen H, Hu H, Tang Z, Wang Z, Guo Q (2015) Rapid loss of lakes on the Mongolian Plateau. Proc Natl Acad Sci USA 112:2281-2286

Wan H, Bai Y, Hooper DU, Schönbach P, Gierus M, Schiborra A, Taube F (2015) Selective grazing and seasonal precipitation play key roles in shaping plant community structure of semi-arid grasslands. Landscape Ecol. doi:10.1007/ s10980-015-0252-y

Wang L, Liu C, Alves DG, Frank DA, Wang D (2013) Plant diversity is associated with the amount and spatial structure of soil heterogeneity in meadow steppe of China. Landscape Ecol. doi:10.1007/s10980-013-9955-0

Wu J, Naeem S, Elser J, Bai Y, Huang J, Kang L, Pan Q, Wang Q, Hao S, Han X (2015a) Testing biodiversity-ecosystem functioning relationship in the world's largest grassland: overview of the IMGRE project. Landscape Ecol. doi:10. 1007/s10980-015-0155-y

Wu JG, Zhang Q, Li A, Liang C (2015b) Historical landscape dynamics of Inner Mongolia: patterns, drivers, and impacts. Landscape Ecol. doi:10.1007/s10980-015-0209-1

Yuan F, Wu J, Li A, Rowe H, Bai Y, Huang J, Han X (2015) Spatial patterns of soil nutrients, plant diversity, and aboveground biomass in the Inner Mongolia grassland: 
before and after a biodiversity removal experiment. Landscape Ecol. doi:10.1007/s10980-015-0154-Z

Zhao X, Hu H, Shen H, Zhou D, Zhou L, Myneni RB, Fang J (2014) Satellite-indicated long-term vegetation changes and drives in the Mongolian Plateau. Landscape Ecol. doi:10.1007/s10980-014-0095-y
Zhou D, Zhao X, Hu H, Shen H, Fang J (2015) Long-term vegetation changes in the Four Mega-Sandy Lands in Inner Mongolia. Landscape Ecol, China. doi:10.1007/s10980015-0151-2 